Abstract 271 Table 2 Median OS and TFST from initiation of system treatment for recurrent/metastatic disease after advanced diagnosis

\begin{tabular}{|c|c|c|c|c|c|c|c|}
\hline & & $\begin{array}{l}\text { All patients } \\
\left(\mathrm{N}=2169^{*}\right)\end{array}$ & $\begin{array}{c}\text { Uterine } \\
\text { serous } \\
\text { carcinoma } \\
(n=536)\end{array}$ & $\begin{array}{l}\text { Endometrioid } \\
\text { carcinoma } \\
\qquad(n=1307)\end{array}$ & $\begin{array}{c}\text { Clear-cell } \\
\text { carcinoma } \\
(n=87)\end{array}$ & $\begin{array}{l}\text { Carcino- } \\
\text { sarcoma } \\
(n=29)\end{array}$ & $\begin{array}{c}\text { EC not } \\
\text { otherwise } \\
\text { specified } \\
(n=210)\end{array}$ \\
\hline \multirow{6}{*}{ os $^{\dagger}$} & Median OS $(95 \% \mathrm{Cl})$, months & $49.6(43.9-52.0)$ & $31.3(27.7-34.3)$ & $70.8(60.5-83.2)$ & $29.2(18.3-57.0)$ & $14.4(7.9-53.1)$ & $40.7(21.4-48.1)$ \\
\hline & Interquartile range for median OS, months & $18.1-89.5$ & $15.4-61.8$ & 28.4-NE & 16.1-NE & $6.8-53.1$ & 8.2-NE \\
\hline & Patients with event, $\mathrm{n}$ & 798 & 254 & 394 & 38 & 16 & 96 \\
\hline & Censored patients, $\mathrm{n}$ & 1371 & 282 & 913 & 49 & 13 & 114 \\
\hline & Median follow-up $(95 \% \mathrm{Cl})$, months & $33.0(30.6-35.0)$ & $32.2(26.1-36.3)$ & $33.7(31.0-35.6)$ & $30.4(22.2-33.9)$ & $24.1(12.0-33.0)$ & $35.6(26.8-43.3)$ \\
\hline & Interquartile range for median follow-up, months & $14.9-52.0$ & $14.5-51.6$ & 24.8-NE & 16.1-NE & $12.0-33.0$ & 8.2-NE \\
\hline \multirow{5}{*}{ TFST $^{\dagger}$} & Median TFST $(95 \% \mathrm{Cl})$, months & $13.6(12.1-15.0)$ & $10.6(9.6-12.3)$ & $18.9(15.8-21.7)$ & $10.8(7.7-16.3)$ & $9.6(6.7-20.2)$ & $8.3(6.0-10.7)$ \\
\hline & Patients with event, $\mathrm{n}$ & 1297 & 381 & 697 & 60 & 19 & 140 \\
\hline & Censored patients, $\mathrm{n}$ & 872 & 155 & 610 & 27 & 10 & 70 \\
\hline & Median follow-up ( $95 \% \mathrm{Cl})$, months & $34.0(31.2-36.7)$ & $37.8(34.4-40.6)$ & $31.7(29.5-35.0)$ & $30.6(22.2-51.4)$ & $25.7(12.0-86.8)$ & $42.3(31.7-45.7)$ \\
\hline & Interquartile range for median follow-up, months & $15.4-52.4$ & $16.5-57.2$ & $14.5-51.8$ & $21.4-52.8$ & $12.0-86.8$ & $19.2-58.9$ \\
\hline
\end{tabular}

*Thirty-three patients did not have recorded therapy following AEC diagnosis: 15 with serous-cell carcinoma; 10 with endometrioid carcinoma; five with clear-cell carcinoma; one with carcinosarcoma; and two with endometrial cancer not otherwise specified; ${ }^{\dagger}$ Crude Kaplan-Meier analyses (no adjustment for confounding factors). NE, not estimable

Women aged $\geq 18$ years diagnosed with AEC (initial diagnosis: stage III/IV, or early stage with subsequent locoregional/distal recurrence) between 1 January 2013 and 30 September 2020, inclusive, were eligible provided they received platinum-based chemotherapy at any time following diagnosis and had $\geq 2$ clinical visits. Patients were followed up from initiation of systemic treatment for recurrent/metastatic disease after advanced diagnosis until 31 March 2021, last available follow-up, or death (whichever occurred first). Overall survival (OS) and time to first subsequent therapy or death (TFST) were estimated with Kaplan-Meier methodology.

Result(s)* Overall, 2202 women with AEC were included; most $(82.7 \%)$ were treated in a community setting and pre-

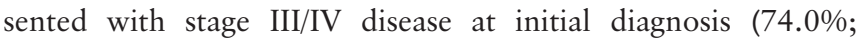
table 1). Compared with other subtypes, a higher proportion (26.3\%) of women with USC were Black/African American. Thirty-three $(1.5 \%)$ patients did not have recorded therapy following AEC diagnosis. The most common first systemic treatments for recurrent/metastatic disease were platinumbased combination chemotherapy (82.0\%), platinum-based single-agent chemotherapy (7.9\%), and platinum-based chemotherapy plus HER2-targeted therapy (2.9\%); median (interquartile range) duration was 9.2 (4.1-23.2) months. Median (95\% confidence interval [CI]) OS from initiation of first systemic treatment was shorter in patients with USC (31.3 [27.7-34.3] months), CCC (29.2 [18.3-57.0] months), and carcinosarcoma (14.4 [7.9-53.1] months) versus the overall population (49.6 [43.9-52.0] months; table 2), as was median TFST from initiation of first systemic treatment (table 2).

Conclusion* In this large real-world study, patients with advanced USC, CCC, and carcinosarcoma had poorer survival outcomes than the overall AEC population, demonstrating an unmet need in these populations, such as the requirement for more effective therapies.

\section{DOSTARLIMAB IN ADVANCED/RECURRENT MISMATCH REPAIR DEFICIENT/MICROSATELLITE INSTABILITY HIGH OR PROFICIENT/STABLE ENDOMETRIAL CANCER: THE GARNET STUDY}

${ }^{1} \mathrm{~A}$ Oaknin*, ${ }^{2} \mathrm{~L}$ Gilbert, ${ }^{3} \mathrm{AV}$ Tinker, ${ }^{4} \mathrm{~J}$ Brown, ${ }^{5} \mathrm{C}$ Mathews, ${ }^{6} \mathrm{~J}$ Press, ${ }^{7} \mathrm{R}$ Sabatier, ${ }^{8} \mathrm{DM}$ O'malley, ${ }^{9} \mathrm{~V}$ Samouëlian, ${ }^{10} \mathrm{~V}$ Boni, ${ }^{11} \mathrm{~L}$ Duska, ${ }^{12} \mathrm{~S}$ Ghamande, ${ }^{13} \mathrm{P}$ Ghatage, ${ }^{14} \mathrm{R}$ Kristeleit, ${ }^{15} \mathrm{C}$ Leath, ${ }^{16} \mathrm{~J}$ Veneris, ${ }^{16} \mathrm{~T}$ Duan, ${ }^{16} \mathrm{E} \mathrm{Im},{ }^{17} \mathrm{~B}$ Pothuri. ${ }^{1}$ Vall $\mathrm{d}^{\prime}$ Hebron University Hospital, Vall d'Hebron Institute of Oncology (VHIO), Barcelona, Spain; ${ }^{2}$ McGill University Health Centre Research Institute, Montreal, Quebec, Canada; ${ }^{3} B C$ Cancer, Vancouver, British Columbia, Canada; ${ }^{4}$ Division of Gynecologic Oncology, Levine Cancer Institute, Atrium Health, Charlotte, NC, USA; ${ }^{5}$ Women and Infants Hospital of Rhode Island, Providence, RI, USA; ${ }^{6}$ Swedish Cancer Institute Gynecologic Oncology and Pelvic Surgery, Seattle, WA, USA; ${ }^{7}$ Department of Medical Oncology, Institut Paoli Calmettes, Aix-Marseille University, Marseille, France; ${ }^{8}$ The Ohio State University - James Comprehensive Cancer Center, Columbus, OH, USA; ${ }^{9}$ Gynecologic Oncology Service, Department of Obstetrics and Gynecology, CHUM, Université de Montréal, Montreal, Quebec, Canada; ${ }^{10}$ START MadridCIOCC, Centro Integral Oncológico Clara Campal, Hospital Universitario HM Sanchinarro, Madrid, Spain; ${ }^{11}$ Emily Couric Clinical Cancer Center, University of Virginia, Charlottesville, VA, USA; ${ }^{12}$ Georgia Cancer Center, Augusta University, Augusta, GA, USA; ${ }^{13}$ Department of Gynecological Oncology, University of Calgary, Calgary, Alberta, Canada; ${ }^{14}$ Guy's and St Thomas' Hospital NHS Foundation Trust, London, UK; ${ }^{15} \mathrm{O}^{\prime} \mathrm{Neal}$ Comprehensive Cancer Center, University of Alabama at Birmingham, Birmingham, AL, USA; ${ }^{16}{ }^{\text {GlaxoSmithKline, }}$ Waltham, MA, USA; ${ }^{17}$ New York University, Department of Obstetrics and Gynecology, NYU Langone Health, Perlmutter Cancer Center, New York, NY, USA

\subsection{6/ijgc-2021-ESG0.131}

Introduction/Background* Dostarlimab is a humanised programmed death (PD-1) receptor monoclonal antibody approved for patients with mismatch mutation repair-deficient/microsatellite instability-high (dMMR/MSI-H) recurrent or advanced endometrial cancer (EC) that progressed on or after a platinum-based chemotherapy regimen. GARNET is a phase 1 study assessing the antitumour activity and safety of dostarlimab monotherapy in patients with advanced solid tumours. 
Abstract 272 Table 1 Antitumour activity

\begin{tabular}{|c|c|c|}
\hline Variable & dMMR/MSI-HEC, n=108 & MMRP/MSSEC, $n=156$ \\
\hline Median follow-up time, mo & 16.3 & 11.5 \\
\hline Objective response rate, ${ }^{3}$ ( $\%, 95 \%$ Cl) & $47(43.5 \%, 34.0-53.4)$ & $22(14.1 \%, 9.1-20.6)$ \\
\hline Complete response, $\mathrm{n}(\%)$ & $11(10.2)$ & $3(1.9)$ \\
\hline Partial response, $n(\%)$ & $36(33.3)$ & $19(12.2)$ \\
\hline Stable disease, $n(\%)$ & $13(12.0)$ & $32(20.5)$ \\
\hline Progressive disease, $n(\%)$ & $39(36.1)$ & $85(54.5)$ \\
\hline Not evaluable, $n(\%)$ & $9(8.3)$ & $17(10.9)$ \\
\hline Disease control rate, ${ }^{\circ} \mathrm{n}(\%)$ & $60(55.6 \%)$ & $54(34.6 \%)$ \\
\hline Response ongoing, $n(\%)$ & 42 of $47(89.4)$ & 14 of $22(63.6)$ \\
\hline Median duration of response (range), mo & Not reached (2.63 to $28.09+)$ & $\begin{array}{c}\text { Not reached (1.54+ to } \\
30.36+)\end{array}$ \\
\hline Kaplan-Meier estimated probability of & & \\
\hline $\begin{array}{l}\text { remainingin response, \% } \\
\text { at } 6 \mathrm{mo}\end{array}$ & 97.9 & \\
\hline at $12 \mathrm{mo}$ & 90.9 & 62.1 \\
\hline at $18 \mathrm{mo}$ & 80.1 & 62.1 \\
\hline
\end{tabular}

Abstract 272 Table 2 Most common adverse events

\begin{tabular}{|c|c|c|c|}
\hline MedDRA preferredterm $n(\%)$ & $\begin{array}{c}\text { dMMR/MSI-HEC } \\
\mathrm{N}=129\end{array}$ & $\begin{array}{c}\text { MMRp/MSSEC } \\
\mathrm{N}=161\end{array}$ & $\begin{array}{l}\text { Overall } \\
\mathrm{N}=290\end{array}$ \\
\hline \multicolumn{4}{|l|}{ Any-grade TRAEs } \\
\hline Fatigue & $17(13.2)$ & $34(21.1)$ & $51(17.6)$ \\
\hline Diarrhoea & $21(16.3)$ & $19(11.8)$ & $40(13.8)$ \\
\hline Nausea & $16(12.4)$ & $24(14.9)$ & $40(13.8)$ \\
\hline \multicolumn{4}{|l|}{ Grade $\geq 3$ TRAEs } \\
\hline Anaemia & $6(4.7)$ & $4(2.5)$ & $8(2.8)$ \\
\hline $\begin{array}{l}\text { Alanine aminotransferase } \\
\text { increased }\end{array}$ & $2(1.6)$ & $2(1.2)$ & $4(1.4)$ \\
\hline Diarrhoea & $2(1.6)$ & $2(1.2)$ & $4(1.4)$ \\
\hline Fatigue & 0 & $4(2.5)$ & $4(1.4)$ \\
\hline Lipase increased & $3(2.3)$ & $1(0.6)$ & $4(1.4)$ \\
\hline \multicolumn{4}{|l|}{ TRAEs leading to discontinuation } \\
\hline $\begin{array}{l}\text { Alanine aminotransferase } \\
\text { increased }\end{array}$ & $1(0.8)$ & $2(1.2)$ & $3(1.0)$ \\
\hline $\begin{array}{l}\text { Aspartate aminotransferase } \\
\text { increased }\end{array}$ & $1(0.8)$ & $1(0.6)$ & $2(0.7)$ \\
\hline Transaminases increased & $2(1.6)$ & 0 & $2(0.7)$ \\
\hline
\end{tabular}

Methodology GARNET is a multicentre, open-label, single-arm study. Here we report on 2 independent expansion cohorts of patients with recurrent or advanced EC that progressed on or after a platinum-based chemotherapy regimen. Patients were assigned to cohort A1 (dMMR/MSI-H EC) or cohort A2 (mismatch mutation repair-proficient/microsatellite-stable [MMRp/ MSS] EC) based on immunohistochemistry testing. Patients received $500 \mathrm{mg}$ of dostarlimab intravenously once every 3 weeks for 4 cycles, then $1000 \mathrm{mg}$ once every 6 weeks until disease progression, discontinuation or withdrawal. The primary endpoints are objective response rate (ORR) and duration of response by blinded independent central review using RECIST version 1.1.

Result(s)* In total, $129 \mathrm{dMMR} / \mathrm{MSI}-\mathrm{H}$ and $161 \mathrm{MMRp} / \mathrm{MSS}$ patients were enrolled and dosed. Of these, $108 \mathrm{dMMR} / \mathrm{MSI}-$ $\mathrm{H}$ and $156 \mathrm{MMRp} / \mathrm{MSS}$ patients who had measurable disease at baseline and $\geq 6$ months of follow-up were included for efficacy analyses. ORR and disease control rate (DCR) for dMMR/MSI-H EC was $43.5 \%$ and $55.6 \%$, respectively; ORR and DCR for MMRp/MSS EC was $14.1 \%$ and $34.6 \%$, respectively (table 1$)$. Overall, 16 patients $(5.5 \%)$ discontinued treatment due to a treatment-related adverse event (5 dMMR/MSIH, 11 MMRp/MSS). Table 2 shows safety by cohort and overall. No deaths were attributed to dostarlimab.

Conclusion* Dostarlimab demonstrated durable antitumour activity in both dMMR/MSI-H and MMRp/MSS advanced/ recurrent EC. dMMR/MSI-H status was associated with a higher response rate. DCR achieved in MMRp/MSS EC was noteworthy, considering MMRp/MSS tumours are historically associated with a poor prognosis. The dostarlimab safety profile was manageable.

Clinical trial registration NCT02715284

\section{UNIVERSAL SCREENING FOR MISMATCH REPAIR DEFICIENCY IN ENDOMETRIAL CANCER PATIENTS: IMPLICATIONS FOR CLINICAL PRACTICE}

1;2M Sobočan, ' $\mathrm{L}$ Al Mahdawi, ${ }^{1} \mathrm{~A}$ Cokan, ${ }^{1 ; 2} \mathrm{~A}$ Dovnik, ${ }^{1 ; 2}{ }^{2} \mathrm{M}$ Pakiž, ${ }^{3} \mathrm{~K}$ Gornik Kramberger,

${ }^{3} \mathrm{R}$ Kavalar, ${ }^{1 ; 2}$ J Knez*. 'Maribor University Medical Centre, Divison of Gynecology and Perinatology, Maribor, Slovenia; ${ }^{2}$ UNIVERZA V MARIBORU MEDICINSKA FAKULTETA, Maribor, Slovenia; ${ }^{3}$ Maribor University Medical Centre, Department of Pathology, Maribor, Slovenia

\subsection{6/ijgc-2021-ESG0.132}

Introduction/Background* Universal screening for mismatch repair deficiency (MMRd) in endometrial cancer has been included as a component of the integrated molecular risk assessment and can be used for screening patients with a genetic predisposition for cancer (eg. Lynch syndrome). MMR status is also emerging as an important marker for choosing candidate patients for immunotherapy. We designed a study to evaluate the characteristics of patients with MMR deficient tumours and the impact screening had on their management. Methodology We included a cohort of consecutively treated women with endometrial cancer in a prospective study between January 2020 to March 2021 at the University Medical Centre Maribor, Slovenia. Cancerous tissue of patients with endometrial cancer was stained using immunohistochemistry (IHC) for the proteins of MMR genes MLH1, PMS2, MSH2 and MSH6. Descriptive statistics are reported in median values (range), categorical variables were evaluated using $\chi^{2}$ and continuous variables were evaluated using the Mann-Whitney U test. Statistical analysis was performed using SPSS version 23.

Result(s)* Fourty-five women with EC were identified. Fifteen women (33.3\%) had IHC MMRd tumours and 30 women (66.7\%) had MMR proficient (MMRp) tumours. Women with MMRd tumours were older $(\mathrm{p}<.015)$ with a median age of 72.0 years (49-87) vs. 62.5 years $(32-82)$ and had significantly more frequent deep myometrial invasion $(\mathrm{p}<.027)$ as well as lymphovascular space invasion $(\mathrm{p}<.028)$ of tumours. There was no significant difference between tumour grade $(\mathrm{p}>.069)$. Three women (6.7\%) fulfilled traditional criteria for genetic counselling referral. Based on the implementation of universal MMR testing, 15 (33.3\%) women with MMRd tumours were additionally identified as candidates for genetic counselling.

Conclusion* Universal MMR testing enables a more personalised risk score and the identification of women with a genetic predisposition for cancer in which EC might present as the »sentinel cancer«. Cost effective screening could improve personalised care and future cancer prevention.

\section{STEP BY STEP LAPAROSCOPIC HYSTERECTOMY WITH PELVIC AND PARAAORTIC LYMPHADENECTOMY. ANATOMICAL LANDMARKS}

K Nowak, Z Borowiec*, A Machnicka-Rusek, E Milnerowicz-Nabzdyk. SPZOZ Opolskie Centrum Onkologii im. prof. Tadeusza Koszarowskiego, Opole, Poland

\subsection{6/ijgc-2021-ESG0.133}

Introduction/Background* Surgical management of endometrial cancer is initial treatment for most patients and in early stages of disease is usually curative.The first laparoscopic treatment for endometrial cancer was described by Childers in 1993. Since then, indications for laparoscopic surgery are rising. Comprehensive staging of endometrial cancer guides the use 